\title{
Examining body image and its relationship to exercise motivation: An 18-week cardiovascular program for female initiates with overweight and obesity
}

Authors' Contribution:

A - Study Design

B - Data Collection

C - Statistical Analysis

D - Data Interpretation

E - Manuscript Preparation

F - Literature Search

$\mathrm{G}$ - Funds Collection

\author{
Erin S. Pearson ${ }^{1}(\mathrm{ABCDEF})$, Craig R. Hall ${ }^{2}$ (ACDEG) \\ ${ }^{1}$ Faculty of Health and Behavioural Sciencies, School of Kinesiology, Lakehead Uni- \\ versity, Canada \\ ${ }^{2}$ Faculty of Health Sciencies, School of Kinesiology, Western University, Canada
}

Key words: body image, exercise motivation, physical activity, women, overweight/obesity

Material/Methods: Participants $(n=37$; mean weight $=83.8 \mathrm{~kg}$; mean waist circumference $=38.3$

\section{Abstract}

Background: A healthy body image is related to better psychological well-being and can also impact one's likelihood to engage in health promoting behaviours such as exercise. To date, there has been a paucity of research investigating the relationship between body image and Self-Determination Theory's motivational regulations as a function of exercise participation. The purpose of this study was to examine these constructs over the course of an 18-week cardiovascular-based program for female initiates aged 18-45 with overweight and obesity.

inches) were provided with a personalized exercise program and asked to complete the Multidimensional Body-Self Relations Questionnaire and the Behavioural Regulations in Exercise Questionnaire-2 at four different time-points (i.e., baseline and every six weeks).

Results: Significant improvements to body image constructs were observed over time indicating that feelings of satisfaction with aspects of appearance, as well as physical attractiveness were enhanced (e.g., Appearance Evaluation, $p<0.001, \eta^{2}=0.59$ ). Participants also felt increasingly invested in being physically fit up to week 12 of the program (e.g., Fitness Orientation, $p<0.01, \eta^{2}=0.19$ ). Significant relationships were observed between appearance-related body image and the more self-determined forms of exercise motivation (e.g., Body Areas Satisfaction and Intrinsic Regulation, $r=0.50$, $p=0.001$ ).

Conclusions: Implications of focusing on these variables within physical activity interventions are discussed and underscore the important role that body satisfaction plays with respect to exercise motivation in this particular population.

Word count: 4,880

Tables: 3

Figures: 0

References: 59

\section{Corresponding author:}

Erin Pearson, Ph.D.

Assistant Professor

Faculty of Health and Behavioural Sciences

School of Kinesiology, Lakehead University

Thunder Bay, Ontario, CANADA P7B 5E1

Phone: 807-343-8481

E-mail: erin.pearson@lakeheadu.ca
Received: November 2012

Accepted: May 2013

Published: June 2013 


\section{Introduction}

Despite the fact that the benefits of regular physical activity have been well established [1, 2 , 3], a significant portion of the population fails to engage in the activity levels necessary to elicit positive health outcomes [4]. Among Canadians, $52 \%$ are considered inactive: a trend that is more prevalent among women than men [4]. For those who do begin an exercise program, attrition rates approximate $50 \%$ within the first 6 months [5]. One marked consequence of a physically inactive lifestyle is weight gain [6]. In fact, overweight and obesity have become a major public health concern, identified as risk factors for a multitude of chronic and non-communicable diseases [7, 8, 9]. Thus, a need exists to investigate the determinants regarding physical activity participation among those who fall beyond a healthy weight range, and this is especially the case among women.

Although a number of studies have examined the physiological co-morbidities associated with excess body weight, the impact on psychological health is less understood [10, 11, 12]. One construct that has been identified as a salient psychosocial consequence and predictor of overweight and obesity is negative body image $[13,14]$. Defined as multi-dimensional, body image reflects one's self-perceptions and attitudes toward his/her body, particularly in relation to its appearance $[15,16]$. Women have been shown to be more dissatisfied with their bodies than men [10]; it has been estimated that $45 \%$ of women are making an effort to lose weight at any given time [17], and this value increases to $60 \%$ for those who are overweight [18]. In light of the societal aesthetic standard of a lean and toned body that has been set for women [19, 20], it is not surprising that the desire for an approved appearance has been cited frequently as a motivator for weight loss [21, 22]. As women become more exposed to images of this thin ideal, they often begin to internalize this standard so that it becomes the reference point against which they judge themselves. Changing one's physique in an effort to meet this ideal can be challenging, and efforts are rarely successful [23], which can lead to a negative body image [20].

Because negative body image has been associated with detrimental outcomes including emotional distress, anxiety, depression, and eating disorders [24], it has been suggested that there is a need for the development of interventions which address the increasing number of individuals with body image difficulties [25].

A healthy body image is related to better psychological well-being; more specifically, it has been correlated positively with improved self-esteem [26] and can also impact one's motivation to engage in health promoting behaviours[27]. Exercise is one intervention that has been identified as a practical, cost-effective, and very accessible means to ameliorate negative body image [24, 28, 29]. Based on their meta-analysis, Campbell and Hausenblas [24] argued that enhanced perceptions of body image may occur because an individual feels that his/her body is improving through the exercise experience. In light of the fact that greater body disturbance has been associated with higher adiposity [30], it stands to reason that interventions seeking to target overweight and obesity should examine body image through the inclusion of an exercise-based component. In doing so, it is important to consider mechanisms which may assist in elucidating the relationship between exercise and body image; gaining a greater understanding of the motives (e.g., health, appearance, fitness, weight loss) underlying exercise participation and adherence is of particular concern [31].

Theories of motivation such as self-determination theory (SDT) are useful for investigating the psychological antecedents and influences of exercise behaviour in intervention settings [32]. SDT $[33,34,35,36]$ focuses on the causes and processes through which individuals acquire motivation for initiating and maintaining behaviours over time [33, 37]. A major component of SDT is a continuum which contains distinct types of motivation that are differentiated by the extent to which they are self-determined or autonomous, versus non-self-determined or controlled [33]. According to this theory, experiencing self-determination is an important requirement for long-term maintenance of behaviours. As behaviours are performed more autonomously, the degree to which they are engaged in with a sense of choice or volition also increases. Amotivation, found at the left end of the continuum, represents a state of lacking the intention to engage in a behaviour [33]. To its right are four extrinsically motivated behavioural dimensions which range in their degree of autonomous regulation and are typically induced by elements found outside of the individual (e.g., rewards). 
These include: external regulation (one's engagement in a behaviour for the purposes of satisfying some type of separable outcome), introjected regulation (a behaviour is performed to enhance selfesteem or alleviate self-imposed feelings of pressure), identified regulation (derived from a sense of motivation towards attaining a personal goal; the action itself is valued although may not be inherently enjoyable), and integrated regulation (a behaviour is performed by choice or for instrumental reasons in order to confirm one's sense of self). To the far right of the continuum is intrinsic motivation which is achieved when individuals derive genuine pleasure or satisfaction as a result of engaging in a behaviour [32, 33, 36]. For a full description and visual representation of SDT, please refer to Ryan and Deci's paper [33].

Research has examined the role of SDT's utility with respect to health behaviour change. In exercise, when compared with individuals who are externally controlled for an action, it has been found that those who possess authentic, intrinsic motivation to complete an action have greater interest and confidence resulting in enhanced performance, persistence, self-esteem, and general well-being [33, 38]. In a physical activity context, Teixeira et al. [39] found that the strongest predictor of long-term results (i.e., weight loss and continued participation) was an increase in intrinsic motivation. Quite often, individuals who begin to exercise for external appearance reasons gradually alter their motives and begin to exercise for physiological and psychological well-being [40]. Given that concerns about body image are frequent motivators for beginning an exercise program [41], not to mention the fact that people often begin to exercise for appearance reasons but alter their motives as they continue exercising [40], examining the role of motivation would seem to be an important consideration when investigating factors associated with the body image-exercise relationship.

To date, there has been a paucity of research investigating the mechanisms behind exerciseinduced body image changes over an extended period of time. In addition, women are motivated frequently to begin an exercise program for appearance-related reasons and little is known regarding how these motives change over time with respect to body image. Therefore, the purpose of the present study was to examine changes in body image and motivational regulations over the course of an 18-week cardiovascular-based program intended for female initiates, as well as the relationship between these two constructs. Because regular aerobic exercise, such as walking, can generally be incorporated into one's lifestyle $[22,42]$ and has been shown to produce elevations to mood, enhanced feelings of mastery and control, as well as improved self-esteem [43], it was determined that the present study would incorporate a cardiovascular-based intervention. It was expected that improvements to body image would occur over time [23, 24]. The research examining the relationship between body image and motivational regulations is limited; however, since exercising for autonomous motives is associated with positive psychological outcomes [44, 45, 46], it was hypothesized that enhancements to body image would be related inversely to the less selfdetermined regulations (i.e., amotivation, external, and introjected regulation) and positively to the more self-determined regulations (i.e., identified regulation and intrinsic motivation) over the course of the intervention.

\section{Material and methods Participants}

Eighty women were recruited to take part in the study [mean $(\mathrm{M})$ age $=33.4$ years, standard deviation $(S D)=7.6$ ]. Eligibility criteria required that participants had a Body Mass Index $(\mathrm{BMI}) \geq$ $25 \mathrm{~kg} / \mathrm{m}^{2}$ and were: (1) initiates (i.e., exercised once or less per week and wanted to begin an exercise program); (2) aged 18 to 45; (3) not pregnant; and (4) not on any type of formal diet. Those who met the inclusion criteria and wished to participate were booked for a baseline assessment. At this initial meeting with the researcher, each participant's height and weight was measured resulting in a mean baseline BMI of $29.02 \mathrm{~kg} / \mathrm{m}^{2}, \mathrm{SD}=4.71$. Waist circumference (WC) was also measured at this time $(M=37.08$ inches, $S D=4.63)$. The ethics review board of the university where the research was conducted approved the study and participants provided written informed consent prior to commencing the program. All aspects of the study were carried out in a private exercise laboratory facility located on the university campus. 


\section{Main outcome measures}

The Multidimensional Body-Self Relations Questionnaire (MBSRQ; [47, 48]). The MBSRQ is a well-validated measure that assesses attitudinal dispositions toward the physical self and has been used previously in overweight and obese samples [11, 13,30]. The 69-items on the questionnaire comprise 10 subscales which measure evaluative, cognitive, and behavioural dimensions related to body appearance, health, and physical functioning [48]. For the purposes of the present study, five of the subscales pertaining to appearance, fitness, and body area satisfaction are reported. Questions were answered based on a 5-point rating scale describing multiple levels of agreement, satisfaction, or concern. A complete description for each of the subscales and their reliabilities can be found in Table 1.

The Behavioural Regulation in Exercise Questionnaire-2 (BREQ-2; [49]). The BREQ-2 is a selfreport index of SDT's exercise regulations and contains five subscales which measure external, introjected, identified, and intrinsic regulation as well as amotivation. It should be noted that integrated regulation is not assessed by this instrument. Following the stem, "Why do you exercise?" participants responded to each item anchored at the extremes by (0) Not true for me and (4) Very true for me. Previous research has examined types of motivation in a physical activity context among women and individuals with overweight/obesity [e.g., 50, 51] and supported the BREQ-2's factor structure and subscale reliability (Cronbach's $\alpha \geq 0.73$; [49]). The reliability ranges of the BREQ-2 subscales for the present study were acceptable (Amotivation, $\alpha=0.78-0.89$; External regulation, $\alpha=0.63-0.86$; Introjected regulation, $\alpha=0.76-0.93$; Identified regulation, $\alpha=0.61-0.85$; Intrinsic regulation, $\alpha=0.84-0.94$ ).

Body composition ${ }^{1}$. Body composition was assessed using Dual-Energy X-Ray Absorptiometry(DXA) at baseline, and at weeks 6, 12, and 18.The GE DXA (Prodigy ${ }^{\mathrm{TM}}$, Lunar Corporation) machine used contains body composition software that provides a direct calculation of weight, total fat, and fat-free mass. Participants' height and waist circumference were measured by the researcher at baseline, and waist circumference was measured additionally at each successive time point (i.e.,weeks 6, 12, and 18).

Cardiovascular fitness. Each participant completed a sub-maximal fitness test which followed the general procedures outlined by The American College of Sport Medicine [52], and was conducted by a kinesiologist certified in fitness appraisal or a trained masters-level researcher.

\section{Procedures}

Baseline assessment. Prior to commencing the cardiovascular exercise program, participants were provided with a detailed letter of information stating that the purpose of the study was to examine how an exercise program could influence exercise cognitions. Once informed consent was acquired, participants were asked to complete the demographic information form, MBSRQ, and BREQ-2; they were then directed to the cardio-respiratory suite to undergo a sub-maximal fitness test.

Exercise prescription. Previous studies have shown that in order to impact body image positively, the intensity of exercise needs to be moderate to high [23, 53]. The prescriptions involved in the present study were assigned in this vein with a view towards invoking improvements in physical function, fitness, and appearance. In addition, a recent meta-analysis [24] examining the impact of exercise interventions on body image revealed that greater exercise frequency per week resulted in larger effect sizes; however, no moderating effect for program length was observed ( $M$ length in weeks $=12.69$ ). Given that a need for greater clarity pertaining to the dose-response relationship and psychological benefits of exercise exists [24], it was determined that a cardiovascular program of an 18-week duration would be implemented for the present study. Based on the results of her sub-maximal fitness test and the resting heart rate

\footnotetext{
${ }^{1}$ Previous research has shown that improvements to body image can occur independent of physiological changes in an exercise context, and that changes to fitness play a minor role in explaining the effects of exercise on body image [29]. We conducted analyses for the present study which corroborated these findings, and therefore determined that the inclusion of these data was not necessary. Participant values for body composition and fitness have been reported in Table 2.
} 
value, each participant was given a personalized cardiovascular program created by a certified fitness trainer. The participants were asked to exercise for 30-45 minutes, three times a week, and to maintain an assigned, pre-determined target heat rate. The target heart rate range percentages were increased every 4-5 weeks beginning with a target heart rate within $50-60 \%$ of her heart rate reserve in week 1, progressing to a target heart rate of $60-70 \%$ of heart rate reserve by week 18 . The prescription also involved a progressive increase in the required number of minutes spent in the target heart rate range throughout the 18-week program. Following the fitness test, a guided tour of the exercise lab occurred. In order to ensure proper technique, the researcher provided a demonstration of the cardiovascular equipment (i.e., treadmills, row machines, step machines, and bicycles), and then observed as the participant tried the equipment on her own.

\section{Data analyses}

For those who completed the program $(n=37)$ the scores for body image and exercise motivation were analyzed to determine if changes occurred over the course of the intervention; separate repeated measures ANOVAs were conducted, and for each analysis time was a withinsubjects variable (baseline, 6-weeks, 12-weeks, 18-weeks). In addition, bivariate correlation analyses were conducted using pre- and post-intervention residualized change scores to examine the relationships between the specific body image and motivation subscales as a function of exercise.

For practical reasons, a control group was not included in the present study. Recruiting sedentary women interested in beginning an exercise program and then assigning them to a control group involving questionnaire completion and no exercise for 18-weeks would be extremely challenging. It would be expected that many of them would drop out of the study since they volunteered to become more active initially. Moreover, randomizing individuals with overweight and obesity to a non-exercise condition could also be considered unethical given the health risks associated with excess adiposity and sedentariness $[7,8,9]$. To compensate for the lack of a control group, an intent to treat analysis was used $(n=80)$, whereby the last observation was carried forward to account for missing data, in order to examine the correlation between the length of time participants remained in the study (measured in weeks and by the number of exercise sessions), and the changes that were demonstrated in the various dependent variables of interest (i.e., body image and motivation). It was expected that the longer participants exercised, the larger the changes in their scores.

\section{Results}

The first analysis was conducted to investigate the changes in body image and motivation over the 18-weeks; only participants completing the four assessments were included (i.e., baseline, 6 , 12, 18 weeks; $n=37$ ). After applying a Bonferroni correction adjustment, repeated measure ANOVAs revealed a significant effect for time in three of the body image measures between baseline and week 18: $\mathrm{AE}\left[F(3,34)=16.13, p<0.001, \eta^{2}=0.59\right]$; $\mathrm{FO}[F(3,34)=34.04, p<0.001$, $\left.\eta^{2}=0.75\right]$ and BASS $\left[F(3,34)=6.95, p=0.001, \eta^{2}=0.38\right]$. Significant changes occurred specifically between baseline and week 6 for $\operatorname{AE}\left[F(1,36)=39.21, p<0.001, \eta^{2}=0.52\right]$; $\operatorname{FO}[F(1,36)=77.92$, $\left.p<0.001, \eta^{2}=0.68\right]$; and $\operatorname{BASS}\left[F(1,36)=15.86, p<0.001, \eta^{2}=0.31\right]$; and between weeks 6 and 12 for $\mathrm{AO}\left[F(1,36)=4.40, p<0.05, \eta^{2}=0.11\right]$; and $\mathrm{FO}\left[F(1,36)=8.66, p<0.01, \eta^{2}=0.19\right]$. No significant changes occurred between weeks 12 and 18 for any of the body image variables. Analysis of the subscales for exercise motivation revealed little change with the exception of a significant effect for time in external motivation between baseline and week six $[F(1,36)=9.3, p$ $\left.<0.01, \eta^{2}=0.21\right]$. Introjected regulation scores approached significance, increasing between weeks 6 and $12\left[F(1,36)=3.8, p=0.06, \eta^{2}=0.09\right]$. The means and standard deviations for the exercise motivation and body image scores at each time point can be found in Table 2.

For those who completed the program, bivariate correlations were conducted to examine the relationship between the specific body image and motivation subscales as a function of exercise. Results revealed significant positive relationships between: $\mathrm{AE}$ and intrinsic regulation $(r=0.38$, $p<.05) ; \mathrm{AO}$ and identified $(r=0.44, p<0.01)$ and intrinsic $(r=0.31, p=0.05)$ regulation; and BASS 
and intrinsic regulation $(r=0.50, p=0.001)$. The relationship between BASS and identified regulation approached significance $(r=0.29, p=0.08)$. In addition, significant negative correlations were found between amotivation and $\mathrm{AO}(r=-0.36, p<0.05)$, and FE $(r=-0.33, p<0.05)$. The correlations for body image and motivation can be found in Table 3.

Correlations between the length of time participants remained in the study $(n=80)$ and the changes that were demonstrated in the various dependent psychological variables of interest revealed a number of significant relationships. For body image, significant positive relationships were observed between several subscales and both total weeks of exercise and total number of exercise sessions suggesting that the longer individuals remained in the program, the higher their body image scores. These included: $\mathrm{AE}(r=0.31, p<0.01 ; r=0.30, p<0.01)$; FO $(r=0.57, p<0.001$; $r=0.57, p<0.001)$; and BASS $(r=0.26, p<0.05 ; r=0.24, p=0.05)$. For SDT's motivational regulations, significant negative relationships were observed for external regulation and both total weeks $(r=-0.78, p<0.001)$ and total sessions $(r=-0.74, p<0.001)$ of exercise. Introjected regulation was negatively and significantly associated with total sessions of exercise $(r=-0.22$, $p<0.05$ ), while significant positive relationships approaching significance were observed for identified regulation and weeks of exercise $(r=0.19, p=0.09)$, as well as intrinsic regulation and total exercise sessions $(r=0.19, p=0.09)$.

Table 1. Description and reliability coefficients for the MBSRQ subscales [49]

\begin{tabular}{|c|c|c|}
\hline $\begin{array}{l}\text { Subscale\& } \\
\text { Number of Items }\end{array}$ & a by time-point & Description \\
\hline $\begin{array}{l}\text { Appearance } \\
\text { Evaluation }(\mathrm{AE}) \\
n=7\end{array}$ & $a=0.85,0.87,0.87,0.87$ & $\begin{array}{l}\text { AE involves feelings of physical attractiveness or unattractiveness regarding } \\
\text { one's looks. Higher scores are associated with positive and satisfying feelings } \\
\text { about physical appearance whereas low scores indicate a general } \\
\text { unhappiness. }\end{array}$ \\
\hline $\begin{array}{l}\text { Appearance } \\
\text { Orientation (AO) } \\
n=12\end{array}$ & $a=0.84,0.89,0.90,0.89$ & $\begin{array}{l}\text { AO describes the extent to which one invests in his or her appearance.High } \\
\text { scorers pay attention to their appearance, perform extensive grooming behav- } \\
\text { iours, and generally place more importance on how they look.Low scorers are } \\
\text { more apathetic towards their appearance, placing little importance on how they } \\
\text { look and expending minimal effort to "look good." }\end{array}$ \\
\hline $\begin{array}{l}\text { Fitness Evalua- } \\
\text { tion (FE) } \\
n=3\end{array}$ & $a=0.77,0.78,0.79,0.82$ & $\begin{array}{l}\text { FE is characterized by feelings of being physically fit or unfit.High scorers } \\
\text { regard themselves as in shape, or athletically competent and active; they also } \\
\text { place value on fitness and are involved in activities which seek to enhance or } \\
\text { maintain their fitness. Low scores represent feelings of being out of shape, or } \\
\text { athletically unskilled; little value is placed on physical fitness and low scorers } \\
\text { do not strive to incorporate regular exercise activities into their lifestyles. }\end{array}$ \\
\hline $\begin{array}{l}\text { Fitness Orienta- } \\
\text { tion (FO) } \\
n=13\end{array}$ & $a=0.73,0.76,0.79,0.80$ & $\begin{array}{l}\text { FO examines the extent to which one invests in being physically fit or athleti- } \\
\text { cally competent.High scorers value fitness and are involved actively in activi- } \\
\text { ties that maintain or enhance their fitness.Low scorers do not place value on } \\
\text { physical fitness and do not incorporate regular exercise into their lifestyles. }\end{array}$ \\
\hline $\begin{array}{l}\text { Body Areas } \\
\text { Satisfaction } \\
\text { (BASS) } \\
n=9\end{array}$ & $a=0.76,0.80,0.80,0.89$ & $\begin{array}{l}\text { The BASS is similar to the AE subscale; however, the BASS focuses more on } \\
\text { specific aspects of one's appearance.Higher scores indicate that individuals } \\
\text { are generally content with most areas of their body.Low scorers are unhappy } \\
\text { with the size and/or appearance of several areas. }\end{array}$ \\
\hline
\end{tabular}


Table 2. Descriptive Statistics for Subscales, Body Composition, and Fitness $(n=37)$

\begin{tabular}{lcccc}
\hline Variable & Baseline & 6 -week & 12-week & 18-week \\
\hline AE & $2.4(0.68)$ & $2.8(0.73)$ & $2.7(0.73)$ & $2.8(0.76)$ \\
AO & $3.3(0.58)$ & $3.3(0.61)$ & $3.2(0.65)$ & $3.2(0.62)$ \\
FE & $3.3(0.73)$ & $3.2(0.82)$ & $3.3(0.79)$ & $3.4(0.77)$ \\
FO & $2.6(0.47)$ & $3.2(0.48)$ & $3.3(0.44)$ & $3.3(0.48)$ \\
BASS & $2.6(0.53)$ & $2.9(0.55)$ & $2.9(0.55)$ & $2.9(0.72)$ \\
Amotivation & $0.25(0.6)$ & $0.25(0.5)$ & $0.32(0.6)$ & $0.22(0.5)$ \\
External Regulation & $0.63(0.6)$ & $0.35(0.6)$ & $0.45(0.6)$ & $0.36(0.6)$ \\
Introjected Regulation & $1.7(1.0)$ & $1.5(1.2)$ & $1.7(1.2)$ & $1.7(1.2)$ \\
Identified Regulation & $2.4(0.7)$ & $2.5(0.7)$ & $2.5(0.7)$ & $2.6(0.9)$ \\
Intrinsic Motivation & $1.9(1.0)$ & $2.2(0.8)$ & $2.1(0.9)$ & $2.2(1.0)$ \\
Weight (kg) & $83.8(16.0)$ & $83.7(15.9)$ & $83.1(15.8)$ & $82.6(15.8)$ \\
WC (in) & $38.3(4.8)$ & $36.8(7.7)$ & $36.9(5.5)$ & $36.7(5.4)$ \\
Fat mass (kg) & $35.4(11.8)$ & $35.0(11.6)$ & $34.8(11.5)$ & $34.4(11.5)$ \\
Fat-free mass (kg) & $48.4(5.3)$ & $48.8(5.4)$ & $48.3(5.3)$ & $48.2(5.3)$ \\
Android fat (\%) & $51.3(7.8)$ & $50.3(7.7)$ & $50.9(7.8)$ & $50.7(7.8)$ \\
Gynoid fat (\%) & $52.7(4.6)$ & $52.4(4.7)$ & $52.1(4.6)$ & $52.2(5.0)$ \\
VO2 max (L/min) & $2.4(0.48)$ & ---------- & ---------- & $2.5(0.38)$ \\
\hline Values are expressed
\end{tabular}

Values are expressed as $M(S D)$

Table 3. Bi-variate Correlations for MBSRQ and BREQ-2 Subscales $(n=37)$

\begin{tabular}{cccccc}
\hline Measure & Amotivation & $\begin{array}{c}\text { External } \\
\text { Regulation }\end{array}$ & $\begin{array}{c}\text { Introjected } \\
\text { Regulation }\end{array}$ & $\begin{array}{c}\text { Identified } \\
\text { Regulation }\end{array}$ & $\begin{array}{c}\text { Intrinsic } \\
\text { Regulation }\end{array}$ \\
\hline AE & -0.15 & -0.02 & -0.08 & 0.16 & $0.38^{*}$ \\
AO & $-0.36^{*}$ & 0.30 & 0.16 & $0.44^{* *}$ & $0.31^{*}$ \\
FE & $-0.33^{*}$ & 0.13 & 0.16 & 0.17 & 0.19 \\
FO & -0.21 & 0.09 & -0.07 & 0.19 & 0.17 \\
BASS & -0.12 & -0.26 & 0.12 & 0.29 & $0.51^{* * *}$ \\
\hline
\end{tabular}

${ }^{*} p \leq 0.05 ;{ }^{* *} p<0.01 ;{ }^{* *} p=0.001$

2

\section{Discussion}

The purpose of this study was to examine changes in body image over time among women with overweight and obesity, and determine specifically whether changes in these dimensions were related to changes in SDT's motivational regulations as a function of participating in an 18-week cardiovascular exercise program. As expected, results revealed significant positive changes to body image during the program pertaining to perceptions of appearance and fitness. That is, participants experienced significant increases to AE and BASS within the first six weeks of the program indicating that feelings of satisfaction with overall and specific aspects of appearance, as well as physical attractiveness increased. In a recent meta-analysis, Campbell and Hausenblas [24] noted that enhanced perceptions of body image may occur because an individual feels that his/her body is improving through the exercise experience. Consistent with this notion, these participants endorsed significant improvements to FO (the extent of investment in being physically fit), not only for the first six weeks of the program, but also between weeks six and 12 which connotes an increased sense of value placed on fitness. According to Cash [48], high FO scorers are strongly involved in activities to maintain or enhance their fitness. The correlational data in the present study support this assertion whereby the longer and more frequently participants exercised, the more 
their FO scores and subsequent investment tended to increase. This was also the case for $A E$, BASS, and exercise adherence: a finding congruent with previous research which has shown a positive significant relationship between BASS and exercise sessions attended among obese women participating in a cardiovascular-based exercise program [54].

Interestingly, little change was observed to the FE construct which measures feelings of being physically fit or unfit. Thus, in this context, it was not necessary for participants to regard themselves as "in shape" or athletically competent in order to experience feeling more satisfied with their appearance. Rather, feeling invested through participating in the physical activity itself and placing value on fitness (i.e., FO) were more salient experiences among these women. Given that low FO scorers do not generally incorporate exercise activities into their lifestyles on a regular basis [48], this is an important finding from an adherence perspective. Based on the present results, and in light of the fact that minimal improvements to body image were observed beyond the 12week time point, incorporating tools and practices that can assist with tapping into participant values in relation to the exercise experience should be considered for future studies (e.g., motivational interviewing via Co-Active life coaching skills $[55,56,57])$.

In an effort to gain an increased insight into the motivational mechanisms behind the body image and exercise relationship, the present study examined body image in relation to SDT's motivational regulations. Previous research grounded in SDT and targeting women in an exercise context has demonstrated significant improvements to the more autonomous forms of self-regulation over time [58, 59]. For example, Silva and colleagues [59] recently evaluated the impact of a 30-session intervention with obese women. The intervention focused, in part, on: building sustainable knowledge supporting informed choice; encouraging self-initiation while limiting prescriptions and demands; providing participants with options; and encouraging participants to explore congruence between their values and lifestyles while providing positive feedback. Results revealed a large intervention effect size for perceived autonomy-promoting treatment climate which is integral for eliciting improvements in the more self-determined regulations. In contrast, no significant motivational changes were observed in the current study over time with the exception of external regulation which decreased significantly between baseline and week six of the program. One possible explanation for the present findings is that a behavioural component was not included as part of the exercise intervention. Focusing more on specific autonomy supporting elements such as those implemented by Silva et al. [59] may have proven efficacious for enhancing the motivational regulations among these particular participants and should be considered for ensuing studies.

Despite minimal change to these regulations in and of themselves, results did reveal a significant positive relationship between $\mathrm{AO}$ and identified regulation which implies that participants were increasingly invested in their appearances, and that this investment was related to their identifying with or valuing the exercise behaviour. Within SDT, if health behaviours such as exercise are to be maintained successfully beyond treatment settings, it is important that individuals do come to place value on the behaviours and endorse their importance on a personal level [37]. Further, for participants in the present study, $\mathrm{AE}, \mathrm{AO}$, and BASS were all significantly correlated with intrinsic motivation suggesting that in this population, improvements to these appearance-related components of body image were related to participants' deriving genuine pleasure or satisfaction through engaging in the exercise. SDT distinguishes between intrinsic life goals (e.g., personal growth, physical health) and extrinsic life goals (fame, physical attractiveness) and posits that focusing more on the former produces greater maintenance to health behaviour changes over time [37]. Although participants in the present study were concerned about their appearance, it may be the case that in populations with obesity, focusing on more external variables such as attractiveness is necessary initially before participants can begin to endorse the performance of physical activity volitionally and enjoyably.

\section{Conclusions}

Strengths. To our knowledge, this is the first study to examine changes in body image over the course of an 18-week cardiovascular exercise program; thus, these data make an important contribution towards our temporal understanding of how body image changes during an exercise pro- 
gram. Based on these results, significant improvements to body image can occur in as little as six weeks and continue up to 12 weeks among women with overweight and obesity who are new to exercise. This is a salient finding given the negative health implications that often accompany these conditions, and the fact that a healthy body image can influence one's likelihood to engage in health promoting behaviours [23, 27]. Although no significant enhancements to body image were observed during the final third of the program, scores did remain stable which highlights the fact that 12 weeks may be a critical intervention length for future body image research. Further, the protocol for the present study did not involve a cognitive-behavioural component and focused entirely on the provision of an 18-week exercise program. Yet, enhancements to body image were still observed and found to be associated with greater participation, thereby underscoring the salient impact that cardiovascular exercise can have on body satisfaction and investment towards fitness. Additionally, few studies to date have examined the relationship between body image and SDT's motivational regulations. This study provides some insight for future studies wishing to examine these constructs with a view towards enhancing autonomy and influencing physical activity adherence rates positively.

Limitations. The results of the present study are informative; however, there are limitations worth considering. First of all, a relatively small sample size was obtained and examined, which may have impacted the findings. In addition, because the current study took place in a private controlled laboratory, the ecological validity of the intervention cannot be ascertained nor the results generalized beyond this type of setting. The inclusion of more lifestyle-based exercise (e.g., in the homes of participants) as part of the intervention protocol should be considered for future studies. Finally, including a comparison group, perhaps one that engaged in another form of physical activity such as resistance training, would have reduced the threats to internal validity (e.g., no control group) inherent in the present study.

Future directions and conclusions. Future studies attempting to replicate the present findings should incorporate a larger sample size in order to uncover optimal conditions for enhancing these cognitions, especially beyond a 12-week period. Given that the present study utilized correlational data to investigate the relationships of interest, exploring the mechanisms between body image and motivational regulations over time is warranted so that inferences pertaining to causation can be made with certainty. Specifically, researchers should focus on potential mediators of this relationship (e.g., self-presentation, self-efficacy, setting, type and amount of exercise) in an effort to identify reasons for attrition while uncovering additional ways to enhance autonomy, thereby increasing the probability of long-term adherence.

\section{Acknowledgements}

This work was supported by the Social Sciences and Humanities Research Council of Canada Igrant number 410-2007-1559].

\section{References}

1. Melzer K, Kayser B, Pichard C. Physical activity: the health benefits outweigh the risks. Curr Opin ClinNutr. 2004;7:641-647.

2. Penedo FJ, Dahn JR. Exercise and well-being: a review of mental and physical health benefits associated with physical activity. Curr Opin Psychiatr. 2005;18:189-193.

3. Benefits of physical activity. Public Health Agency of Canada; 2010. Available at [http://www.phacaspc.gc.ca/hp-ps/hl-mvs/pa-ap/index-eng.php]. [Accessed April 23, 2009].

4. Physical activity levels among Canadian adults. Canadian Fitness and Lifestyle Research Institute; 2008. available at [http://www.cflri.ca/eng/levels/adult_levels.php]. [Accessed April 2, 2009].

5. Dishman RK, Buckworth J. Increasing physical activity: A quantitative synthesis. Med Sci Sport Exer. 1996;28:706-719.

6. King GA, Fitzhugh EC, Bassett DR, et al. Relationship of leisure-time physical activity and occupational activity to the prevalence of obesity. Int J Obes. 2001;25:606-612.

7. Statistics Canada. Health Reports (Catalogue no. 82-003-XPE, 17(3)). Ottawa, Ontario, Canada: Health Statistics Division; 2006. 
8. Lau DCW, Douketis, JD, MorrisonKM, Hrmiak IM, Sharma AM. 2006 Canadian clinical practice guidelines on the management and prevention of obesity in adults and children [summary]. Can Med Assoc J. 2007;176:1-13.

9. Obesity and overweight. World Health Organization. Available at [http://www.who.int/mediacentre/ factsheets/fs311/en/index.html]. [Accessed April 23, 2009].

10. Schwartz MB, Brownell KD. Obesity and body image. Body Image. 2004;1:43-56.

11. Annis NM, Cash TF, Hrabosky JI. Body image and psychosocial differences among stable average weight, currently overweight, and formerly overweight women: The role of stigmatizing experiences. Body Image. 2004;1:155-167.

12. van der Merwe MT. Psychological correlates of obesity in women. Int J Obes. 2007;31:14-18. doi:10.1038/sj.ijo.0803731

13. Foster GD, Wadden TA, Vogt RA. Body image in obese women before, during and after weight loss treatment. Health Psychol. 1997;16:226-229.

14. Matz PE, Foster GD, Faith MS, Wadden TA. Correlates of body image dissatisfaction among overweight women seeking weight loss. J Consult Clin Psych. 2002;70:1040-1044.

15. Cash TF,Pruzinsky T, editors.Body images: Development, deviance, and change. New York NY: Guildford Press; 1990.

16. Cash TF, Morrow JA, Hrabosky JI, PerryAA. How has body image changed? A cross-sectional investigation of college women and men from 1893-2001. J ConsultClin Psych 2004;72:1081-1089.

17. Grediagin M, Cody M, Rupp J, Benardot D, Shern R. Exercise intensity does not effect body composition change in untrained, moderately overfat women.J Am Diet Assoc. 1995;95:661-665.

18. Bish CL, Blanck HM, Serdula MK, Marcus M, Kohl HW, Khan LK. Diet and physical activity behaviours among Americans trying to lose weight: 2000 behavioral risk factor surveillance system. Obes Res. 2005; 13:596-607.

19. Thompson JK, Heinberg LJ, Altabe M, Tantleff-Dunn S. Exacting beauty: Theory, assessment and treatment of body image disturbance. Washington, DC: American Psychological Association; 1999.

20. Tiggemann M. Media influences on body image development. In: Cash TF, Pruzinsky T, editors. Body image: A handbook of theory, research, and clinical practice. New York NY: The Guilford Press; 2002, 91-98.

21. Rosen JC. Body image assessment and treatment in controlled studies of eating disorders. Int $\mathrm{J}$ Eat Disorder. 1996;20:331-343.

22. Anderson LA, Eyler AA, Galuska DA, Brown DR, Brownson RC. Relationship of satisfaction with body size and trying to lose weight in a national survey of overweight and obese women aged 40 and older United States. Prev Med. 2002;35:390-396.

23. Hausenblas HA, Fallon EA. Exercise and body image: A meta-analysis. Psychol Health. 2006;21:33-47.

24. Campbell A, Hausenblas $\mathrm{H}$. Effects of exercise interventions on body image: A meta-analysis. $J$ Health Psychol. 2009;14:780-793.

25. WilliamsPA, Cash TF. Effects of a circuit weight training program on the body images of college students. Int J Eat Disorder. 2001;30:75-82.

26. Miller CT, Downey KT. A meta-analysis of heavyweight and self-esteem. Pers Soc Psychol Rev. 1998;31:68-84.

27. McDonald K, Thompson KJ. Eating disturbances, body image dissatisfaction, and reasons for exercising: Gender differences and correlational findings. Int J Eat Disorder. 1992;11:289-292.

28. Martin KA, Lichtenberger CM. Fitness enhancement and body image change. In: Cash TF, Pruzinsky T, editors. Body image: A handbook of theory, research, and clinical practice. New York NY: Guilford Press; 2002, 414-421.

29. Martin Ginis KA, Bassett RL.Exercise and changes in body image. In: Cash TF, Smolak L, editors. Body image: A handbook of science, practice, and prevention. New York NY: Guilford Press; 2011, 378-386.

30. Friedman KE, Reichmann SK, Costanzo PR, Musante GJ. Body image partially mediates the relationship between obesity and psychological distress. Obes Res. 2002;10:33-41.

31. Ingledew DK, Markland D. The roles of motives in exercise participation. Psychol Health. 2008;23:807828.

32. Hagger M,Chatzisarantis N. Self-determination theory and the psychology of exercise. Int Rev Sport Exerc Psychol. 2008;1:79-103.

33. Ryan RM, Deci EL. Self-determination theory and the facilitation of intrinsicmotivation, social development, and well-being. Am Psychol. 2000;55:68-78.

34. Ryan RM, Deci EL. To be happy or to be self-fulfilled: A review of research on hedonic and eudaimonic well-being. In: Fiske S, editor. Annual review of psychology. Palo Alto CA: Annual Reviews; 2001,141166. 
35. Deci EL, Ryan RM. The "what" and "why" of goal pursuits: Human needs andthe self-determination of behavior. Psychollnq. 2000;11:227-268.

36. Deci EL, Ryan RM. Handbook of self-determination research. Rochester, NY: University of Rochester; 2002.

37. Ryan RM, Patrick H, Deci EL, Williams GC. Facilitating health behavior change and its maintenance: Interventions based on self-determination theory. Euro Health Psychol. 2008;10; 2-5.

38. Ryan RM, Frederick CM, Lepes D, Rubio N, Sheldon KM. Intrinsic motivation and exercise adherence. Int J Sport Psychol. 1997;28:335-354.

39. Teixeira PJ, Going SB, Houtkooper LB, et al. Exercise motivation, eating, and body image variables as predictors of weight control. Med Sci Sport Exer. 2006;179-188.

40. Ingledew D, Markland D, Medley AR. Exercise motives and stages of change. J Health Psychol. 1998;3:477-489.

41. Rodgers WM, Gauvin L. Contributions and comparisons of personal strivings and outcome expectancies in the understanding of participation motives and exercise adherence (University of Alberta, Department of Physical Education and Sport Studies Rep. No. 922R010); 1994.

42. Arbour KP, Martin Ginis KA. Improving body image one step at a time: Greater pedometer step counts produce greater body image improvements. Body Image. 2008;5:331-336.

43. Tiggemann M, Williamson S. The effect of exercise on body satisfaction and self-esteem as a function of gender and age. Sex Roles. 2000;43:119-127.

44. Mullen E, Markland D. Variations in self-determination across the stages of change for exercise in adults. Motiv Emotion. 1997;21:349-362.

45. Wilson PM, Rodgers WM. The relationship between exercise motives and physical self-esteem in female exercise participants: An application of Self-Determination Theory. J Appl Biobehav Res. 2002;7:30-43.

46. Wilson PM, Rodgers WM. The relationship between perceivedautonomy support, exercise regulations and behavioural intentions in women. Psychol Sport Exerc. 2004;5:229-242.

47. Brown TA, Cash TF, Mikulka PJ. Attitudinal body-image assessment: Factor analysis of the Body-Self Relations Questionnaire. J Pers Assess. 1990;55:135-144.

48. Cash TF. Manual for the Multidimensional Body-Self Relations Questionnaire (3rd rev.). Document available for purchase at the author's Website at [http://body-images.com]; 2000.

49. Markland $D$, Tobin $V$. A modification to the behavioural regulation in exercise questionnaire to include an assessment of amotivation. J Sport Exerc Psy. 2004;26:191-196.

50. Markland $\mathrm{D}$. The mediating role of behavioural regulations in the relationship between perceived body size discrepancies and physical activity among adult women. Hellenic J Psy. 2009;6:169-182.

51. Edmunds J, Ntoumanis N, Duda JL.Adherence and well-being in overweight and obese patients referred to an exercise on prescription scheme: A self-determination theory perspective. Psychol Sport Exerc. 2007;8:722-740.

52. American College of Sports Medicine. Guidelines for exercise testing and prescription.6th ed. Baltimore: Lippincott Williams \& Wilkins; 2000.

53. Lox CL, Martin KA, Petruzzello SJ. The psychology of exercise:integrating theory and practice. Scottsdale AZ: Holcomb Hathaway; 2003.

54. Annesi JJ, Unruh JL. Relations of exercise, self-appraisal, mood changes and weight loss in obese women: Testing propositions based on Baker and Brownell's (2000) model. Am J Med Sci. 2008;335:198-204.

55. Whitworth L, Kimsey-House K, Kimsey-House H, Sandahl P. Co-Active coaching: New skills for coaching people toward success in work and life. $2^{\text {nd }}$ ed. California: Davies-Black Publishing; 2007.

56. Newnham-Kanas C, Morrow D, Irwin J. A functional juxtaposition of three methods for health behavior change: motivational interviewing, coaching, and skilled helping. Int $\mathrm{J}$ Evid Based Coach Mentor. 2010;8:27-48.

57. Pearson E. The 'how to' of health behaviour change brought to life: a theoretical analysis of the CoActive coaching model and its underpinnings in self-determination theory. Coaching: Int $\mathrm{J}$ Theory Res Prac 2011;4:89-103.

58. Rodgers WM, Hall CR, Duncan LR, Pearson E, Milne M. Becoming a regular exerciser: Examining changes in behavioural regulations among exercise initiates. Psychol Sport Exerc. 2010;11:378-386.

59. Silva MN, Vieira PN, Coutinho SR, et al. Using self-determination theory to promote physical activity and weight control: a randomized controlled trial in women. J Behav Med. 2010;33:110-122. 